\title{
A mitologia na representação cultural da cachaça: imagem negativa e tentativa de ressignificação
} Daniella Ramos Silva e Sérgio Carvalho Benício de Mello

\section{Resumo}

Foram identificados os mitos que permeiam a cachaça na cultura brasileira, tendo por base 0 fato de eles favorecerem a representação cultural - imagem de uma cultura sobre determinado objeto - negativa desta bebida. Constitiu-se um corpus de pesquisa caracterizado por guardar vínculos significativos com a prática social em foco. A metodologia adotada foi a semiologia. Assim, foram identificados cinco mitos relacionados à representação cultural da cachaça: "cachaceiro", "desprestígio", "bebida popular", "Brazilian brandy" e "da moda". Concluiu-se que, ao contrário do que se supunha antes no início do estudo, os mitos não atribuem única e exclusivamente conotações negativas à cachaça no Brasil; conferem-lhe também conotações positivas. Entretanto, os mitos positivos ainda não conseguem ressignificar a representação cultural dessa bebida.

\section{Palavras-chave}

Cachaça. Representação cultural. Mitologia.

Daniella Ramos Silva I daniellaramossilva@hotmail.com Mestre em Administração pela Universidade Federal de Pernambuco (UFPE). Professora do Centro Acadêmico do Agreste - CAA/UFPE.

\section{Sérgio Carvalho de Mello I sergio.benici@@gmail.com}

Tem formação na área de Administração de Empresas, Doutor pela City University London (Cass Business School), Reino Unido (1997). Professor Associado da Universidade Federal de Pernambuco e bolsista de produtividade em pesquisa do CNPq, com experiência nas áreas de ensino e pesquisa em Administração atuando principalmente com os seguintes temas: Inovação Organizacional e Tecnológica; Gestão de Tecnologias Emergentes; Sistemas Inteligentes de Mobilidade; Cibercultura e Espaço Urbano.

\section{Introdução}

A cachaça começou a fazer parte da história brasileira no período de ascensão da indústria açucareira. Ela foi "descoberta" por acaso durante o processo de produção do açúcar mascavo, da rapadura e do melaço nos engenhos do período colonial brasileiro (CASCUDO, 2006).

Como consequência de um processo de evolução natural, de alguma forma os escravos aprenderam a destilar a garapa azeda - espuma "suja e feculenta" formada na superfície dos tachos da produção de açúcar, a qual era retirada à alimentação de animais e de escravos -, convertendo-a em cachaça. E, pouco a pouco, essa bebida se tornou popular entre os escravos e outras pessoas de baixa renda da colônia (CASCUDO, 2006).

Pode-se dizer que o Brasil e a cachaça são contemporâneos. Contudo, apesar de a história de ambos ser indissociável, a bebida possui uma representação cultural bem diferente daquela do Brasil para os brasileiros. A representação dela, 
diferentemente da do Brasil, é permeada por mitos, alguns deles estigmatizantes, a exemplo de: a) que a cachaça é uma bebida de qualidade ruim; $b$ ) que a cachaça é uma bebida destinada a pessoas de baixa renda; c) que a cachaça encontra-se apenas em "botecos"; e d) que cachaça está diretamente ligada à identidade do cachaceiro.

Observa-se que a cachaça tem significado definido, o que ela representa literalmente, o que está e é inerente a ela - uma bebida alcoólica. 0 signo da cachaça, no entanto, foi ressignificado várias vezes desde a colonização, ao ser associado à qualidade ruim, pessoas de baixa renda, "botecos" e à identidade do cachaceiro. Com efeito, ela não é vista mais apenas como uma bebida alcoólica. Na verdade, uma nova significação atribuiu a ela um "espírito" de desqualificação, como uma propriedade natural.

Na representação cultural - imagem de uma cultura ou grupo de pessoas sobre determinado objeto -, os membros de uma cultura usam a linguagem, nesse caso os mitos discutidos a priori e, possivelmente, localizados a posteriori, que serão explicados detalhadamente na próxima seção, para produzir significado a um artefato cultural. Portanto, reitera-se que a cachaça sofre preconceitos devido aos mitos inerentes à cultura brasileira.

De fato, o objetivo deste estudo é identificar os mitos que permeiam a cachaça na cultura brasileira, tendo em vista que eles favorecem a representação cultural negativa da bebida.

\section{Mitologia em Roland Barthes}

Nesse estudo foi considerada a obra "Mitologias" de Roland Barthes (1993) - devido à sua relevância. A partir do desenvolvimento de sua obra, ele passou a refletir sobre a naturalidade com que a arte, a imprensa e o senso comum mascaram continuamente uma realidade. E, após ter explorado uma série de fatos da atualidade da época, definiu, de forma metódica, o mito, que é explicado a seguir.

0 mito é uma fala, mas não uma fala qualquer, já que existem condições especiais para que a linguagem se transforme em mito. É a fala (parole) definida por Saussure (BARTHES, 1993), representando a parte puramente individual, ou seja, a combinação particular dos signos existentes no sistema da língua, feita pelo usuário falante. Assim, pode-se dizer que o mito é uma mensagem, é um modo de significação em que a sociedade tem um papel ativo (BARTHES, 1993 p. 131).

Afala é uma mensagem que pode ser formada por escritas, representações, fotografias, cinema, reportagens, esportes, espetáculos, publicidade, entre outras formas. Todas as matérias-primas do mito pressupõem uma consciência significante e por essa razão se pode raciocinar sobre ele, independentemente das matérias-primas. Toda unidade ou toda síntese significativa poderá ser fala se significar alguma coisa. Isto não quer dizer que se deva tratar a fala mítica como a língua, pois o mito depende de uma ciência geral extensiva 
à linguística, que é a semiologia (BARTHES, 1993 p. 132).

Como estudo de uma fala, a mitologia é apenas um fragmento da semiologia, que é uma ciência que estuda as significações, independentemente dos seus conteúdos. Como também a semiologia sozinha não explica a mitologia. Por conseguinte, é importante perceber que a unidade de uma explicação depende da coordenação dialética das ciências particulares que nela estão engajadas. Então, a mitologia faz parte simultaneamente da semiologia, como ciência formal, e da ideologia, como ciência histórica (BARTHES, 1993 p. 133).

Toda semiologia relaciona dois termos, 0 significante e o significado, que levam, portanto, a um terceiro termo, o signo, o total associativo dos dois termos anteriores. No plano de análise, não se pode confundir significante, significado e signo. Naturalmente, existem entre eles implicações funcionais (como a da parte ao todo) que podem fazer a análise parecer desnecessária, mas essa distinção tem grande importância para o estudo do mito como esquema semiológico (BARTHES, 1993 p. 134).
No mito encontram-se 0 esquema tridimensional de significante, significado e signo. Porém, o mito é um sistema particular, visto que ele se constrói a partir de uma cadeia semiológica já existente. Ele é um sistema semiológico segundo. 0 que era signo no primeiro sistema, transforma-se em significante para 0 segundo. Assim, as matérias-primas da fala mítica, desde que são captadas pelo mito, reduzemse à função de significante (BARTHES, 1993 p. 136). Para melhor entendimento, vê-se a figura 1 , abaixo. Logo, pode-se entender que no mito existem dois sistemas semiológicos: um sistema linguístico - a língua - e o próprio mito - a metalinguagem -, uma segunda língua que fala da primeira. 0 semiólogo, então, não deve interrogar-se sobre 0 sistema linguístico. Ele só terá que se preocupar com o signo global, na medida em que este se presta ao mito (BARTHES, 1993 p. 137).

Assim, é possível se entender 0 significado da cachaça por meio da análise da formação de seu mito. 0 s vários mitos sobre a cachaça - dos quais foram identificados, a priori - quatro neste trabalho, contribuem para sua representação cultural ser estigmatizada. 
Vê-se, com mais detalhes, na próxima seção, como essa significação aconteceu na cultura brasileira.

\section{Representação cultural da cachaça}

A representação cultural inclui as práticas de significação, por meio das quais os significados são produzidos (W0ODWARD, 2000). Destaca-se, pois, que ela conecta cultura a significado e linguagem, o que denota usar a linguagem para dizer algo significativo ou para representar o mundo significativo para outras pessoas. Além do mais, a representação é um processo que produz e troca significados entre os membros de uma cultura. Esse processo envolve o uso da linguagem, de signos e imagens para representar algo (HALL, 1997a; 1997b).

Pode-se dizer também que a representação é a produção do significado dos conceitos que estão nas mentes das pessoas. 0 sistema de representações consiste no conceito coletivo sobre algo (CHARTIER, 2002). São as formas de organização, aglomeração, arranjo e classificação de conceitos e da estabilização entre eles. Quando se afirma que pessoas vivem em uma mesma cultura, quer se dizer que elas partilham mapas conceituais. Ou seja, têm uma interpretação do mundo de forma parecida, conceitos das coisas parecidos. Por conseguinte, os mapas conceituais podem ser transformados em signos, que é a transmissão dos conceitos através de elementos como sons, palavras, gestos e expressões (HALL, 1997b).
Enfatiza-se que as representações culturais são sempre determinadas pelos interesses de grupo. Por isso elas não são neutras. Produzem práticas - sociais e políticas - para a legitimação das escolhas e condutas dos indivíduos. Portanto, as representações são supostas de estarem colocadas num campo de concorrência e competições que se efetivam em termos de poder e dominação (GUERRA, 2006; BERGMANN, 2007; FREIRE FILHO, 2005; CHARTIER, 2002).

0 processo histórico da cachaça confirma essa luta ideológica e política de sua representação cultural. A bebida, desde sua origem, foi rejeitada pela elite brasileira, e a partir de então passou a representar um produto ruim $\mathrm{e}$ para pessoas pobres.

Como para Souza (2006) o sujeito não está livre para decidir o que bem quiser, porque está "pressionado" pelas representações impostas pela sociedade, a rejeição da bebida pela elite tende a influenciar também as demais classes sociais.

Assim sendo, as ações dos sujeitos não são só deles. Eles agem de acordo com a história, filiam-se a outras ações de acordo com algo que já foi feito e legitimado. Agem influenciados pelas representações culturais. Ou seja, rejeitam a cachaça porque as pessoas mais influentes e com maior poder a rejeitaram em determinado período histórico e isso foi dado como certo. A representação da cachaça, logo, tornouse estigmatizada por influências culturais, ideológicas e políticas. 
A mídia também produz novas representações através dos discursos divulgados em jornais, revistas, televisão e outros meios (GARCIA; ROCHA; HINERASKY, 2007; CAMPOS, 2006; GUERRA, 2006; SGARBIERI, 2006; FREIRE FILHO, 2005). A mídia pode construir mitos e associar muitos produtos a significados que não correspondem literalmente a eles. Mas, no caso da cachaça, o que se vê no Brasil é que a mídia tentou algumas vezes, porém não conseguiu modificar a sua representação.

A Sagatiba, por exemplo, uma empresa "nova" no setor industrial, apostou no slogan "puro espírito do Brasil" para suas campanhas publicitárias. Apesar de 0 marketing da empresa ser bem feito e de bom gosto, o novo mito que se tentou formar agregando o significado da cachaça a aspectos brasileiros parece não ter feito sentido para 0 povo e, por isso, não foi suficiente para modificar a representação.

Em princípio, tem-se a impressão de que a cachaça carrega uma representação cultural desfavorável no Brasil. No entanto, no exterior, os aspectos históricos em que a cachaça foi introduzida, bem como a publicidade veiculada em alguns países, conseguiram gerar significados positivos à bebida. A tentativa feita pela Sagatiba no Brasil foi efetuada com sucesso por várias outras empresas do setor de cachaça que, desde 1968, exportamna. São exemplos: Ypióca Agroindustrial Ltda, Companhia Müller de Bebidas e
Engarrafamento Pitú Ltda. Fora do País, o significado da cachaça está atrelado à alegria brasileira, ao samba, ao carnaval, ao futebol, entre outros aspectos da cultura. Neste sentido, os exportadores dizem que vender cachaça é como "vender" o Brasil.

\section{A construção de um corpus de pesquisa}

Esta pesquisa apontou para a descoberta dos mitos que permeiam a representação cultural da cachaça no Brasil. A construção de um corpus de elementos significativos e a decisão pelos dados suplementares que foram coletados e usados focalizaram os indivíduos e instituições que obtinham alguma relação significativa com a prática social sob investigação. Assim, o estudo compreendeu os discursos de:

1. Ypióca Agroindustrial Ltda.

\section{Engarrafamento Pitú Ltda.}

\section{Associação Mineiras dos Produtores} de Cachaça de Qualidade (AMPAQ).

4. Instituto Brasileiro da Cachaça (IBRAC).

5. Marcelo Câmara - Expert no tema cachaça na área de consumo, autor do livro "Cachaça Prazer Brasileiro".

6. Livro: Ypióca, 160 anos: A saga de uma família, a história de uma paixão, o segredo de uma lenda.

7. Livro: Cachaça: Prazer brasileiro. 
Os extratos do corpus analítico ora citados foram selecionados a partir de diversas fontes de dados (entrevistas em profundidade, observações e levantamentos bibliográficos), agrupados e categorizados após o trabalho em campo. Ressalta-se que a objetividade deste estudo pode ser avaliada através da qualidade de suas observações e da escolha das fontes de dados e dos entrevistados, com base em uma coerência teórico-epistemológica entre dados e indagações de pesquisa.

0 corpus de pesquisa foi categorizado em dois gêneros discursivos: bibliográfico e entrevista. 0 bibliográfico consistiu na leitura, aálise e categorização em trechos significantes da "representação cultural" dos livros. 0 entrevista consistiu em entrevistas pessoais semi-estruturadas com os sujeitos de pesquisa da Ypióca, Pitú, AMPAQ, IBRAC e com Marcelo Câmara. Logo, depois de transcritas, elas foram categorizadas em trechos significantes da "representação cultural".

\section{Análise do corpus}

A análise do corpus desta pesquisa teve um caráter semiológico, isto é, desvelou os textos obtidos para 0 alcance do objetivo deste estudo. Foi seguida a linha metodológica de Roland Barthes (1996; 1993), o ensaísta, crítico e linguista que procedeu a análise semiológica do mundo social. Com base na semiologia, a ciência que tem como objeto as palavras, os símbolos, os ícones e todos os sistemas de signos atuantes na sociedade, Barthes estudou as significações que podem ser atribuídas à vida social. Ele explicou, então, como as linguagens expressam e como ocultam a realidade.

A seguir, dando início à análise, apresentase 0 repertório com os elementos de representação e consumo da cachaça e seus respectivos significantes.

\subsection{Repertório}

A partir da análise do corpus foram identificados elementos que tratavam de termos referentes à cachaça e significantes que geravam significados a esses elementos. Quando se tratava da representação cultural, por exemplo, em alguns trechos do corpus, utilizava-se 0 elemento "branquinha" para tratar da cachaça industrial e os significantes produto genuinamente brasileiro e preferência nacional para dar significado a tal elemento.

Dessa forma, analisando-se minuciosamente 0 corpus, criou-se um repertório com elementos e significantes para a representação cultural. Observa-se, assim, no quadro 1, o repertório da representação cultural.

0 repertório demonstra um contexto categorizado pronto a ser significado. Entretanto, os significados transmitidos pela cachaça são apropriados à cultura brasileira, ao entendimento dos membros dessa cultura. 0 significado é cultural, tendo em vista ser formado pela representação, um conceito 


\begin{tabular}{|c|c|c|c|}
\hline & \multicolumn{2}{|c|}{ Quadro 1: Repertório da representação cultural } & \\
\hline ELEMENTO & SIGNIFICANTES & ELEMENTO & SIGNIFICANTES \\
\hline \multirow[t]{2}{*}{ 1. "Branquinha" } & $\begin{array}{l}\text { 1.1 Produto genuinamente } \\
\text { brasileiro }\end{array}$ & \multirow{4}{*}{ 5. Público } & 5.1 Trabalhador \\
\hline & 1.2 Preferéncia nacional & & 5.2 Pobre \\
\hline \multirow{4}{*}{ 2. Cachaça artesanal } & 2.1 Prestigio & & 5.3 Classe média \\
\hline & 2.2 Obra de arte & & 5.4 Elite \\
\hline & 2.3 Bebida stuperior & \multirow{2}{*}{ 6. Espaço geográfico } & 6.1 Brasil \\
\hline & 2.4 Imagen de exceléncia & & 6.2 Exterior \\
\hline \multirow{3}{*}{$\begin{array}{l}\text { 3. Cachaça industrial } \\
\text { envelhecida }\end{array}$} & 3.1 Prestigio & \multirow{3}{*}{ 7. Preço } & 7.1 Brasil \\
\hline & 3.2 Imagem boa & & 7.2 Exterior \\
\hline & 3.3 Uisque nacional & & 7.3 Barato \\
\hline \multirow{3}{*}{$\begin{array}{l}\text { 4. Cachaça artesanal } \\
\text { envelhecida }\end{array}$} & 4.1 Prestigio & \multirow{3}{*}{ 8. Antes verstus hoje } & 8.1 Ruim versus boa \\
\hline & 4.2 Bebida stuperior & & 8.2 Ruim versus regular \\
\hline & 4.3 Imagem de excelencia & & 8.3 Ruim versus nuim \\
\hline
\end{tabular}

Fonte: a autora.

coletivo sobre algo (CHARTIER, 2002), e pode ser trazido à mente das pessoas que participam dessa cultura por vários significantes. Para que se alcance o signo, é preciso restabelecer a cadeia de intenções que está por trás do significante que se oferece na cultura brasileira. $\mathrm{E}$ isso só é possível através da reconstituição da estrutura. Os significantes e os significados formam um todo indissolúvel que detém um sentido (BARTHES, 1993).

Vê-se, então, como é possível alcançar o sentido através da metalinguagem.

\subsection{Metalinguagem}

Para se compreender a representação da cachaça, deve-se proceder a uma interpretação de segundo nível - interpretação da metalinguagem. Por sua vez, esta interpretação é 0 desvelamento dos sentidos ocultos dos signos mitológicos (BARTHES, 1993; 1996). Ela pode ser feita de forma alegórica, analógica, tropológica e ideológica (THIRY-CHERQUES,
2008). No caso deste estudo, deu-se de forma ideológica. Interpretou-se ideologicamente 0 repertório da representação cultural, exposto no quadro 1.

A interpretação ideológica procurou mostrar que existem várias ideologias permeando a cachaça e formando seus significados. E, de tais significados, foi possível observar o surgimento de alguns mitos da cultura brasileira relacionados à cachaça.

\subsubsection{Interpretação ideológica}

Os elementos 1, 2, 3 e 4 - "branquinha", cachaça artesanal, cachaça industrial envelhecida e cachaça artesanal envelhecida, respectivamente - tratam de tipos diferentes de cachaça com representações culturais também diferentes. Os significantes 1.1, produto genuinamente brasileiro, e 1.2, preferência nacional, literalmente têm um sentido positivo em relação ao elemento, "branquinha". Porém, mesmo sendo um produto genuinamente brasileiro, 
parece que as pessoas ainda não desejam associar as suas identidades como brasileiros à identidade do consumidor de cachaça - 0 cachaceiro -, pois, na atualidade, o consumo não é uma mera compra de mercadorias, mas um processo de criação de identidades (BARBOSA; CAMPBELL, 2006; SLATER, 2002; MILLER, 1997).

Resultado: surge o mito do cachaceiro.

A preferência nacional é citada, muitas vezes, como sinônimo de destilado mais consumido do Brasil. Entretanto, apenas o fato de ser este destilado não significa que a cachaça seja uma preferência nacional, assim tal afirmação é contestável. Se as pessoas de baixa renda são as principais consumidoras do produto, então, elas podem consumir cachaça porque a preferem ou apenas porque não têm condições financeiras para consumir outro tipo de bebida alcoólica, a cerveja, por exemplo, que é 0 retrato da ascensão social das pessoas de baixa renda e consequente negação da cachaça. Demonstrando, assim, a ação política no contexto, ou seja, a condução do processo social em antagonismos (cachaça e cerveja) concorrentes (MOUFFE, 1996). Por conseguinte, o elemento 1, "branquinha", que é significado por esses dois significantes (1.1 e 1.2) tem uma representação cultural estigmatizada perante a sociedade, relacionada à identidade do cachaceiro e ao público consumidor.

Resultado: surge o mito do desprestígio.
0 elemento 2, cachaça artesanal, tem 0 seu sentido formado pelo significantes 2.1, prestígio, 2.2, obra de arte, 2.3, bebida superior, e 2.4, imagem de excelência. 0 elemento 3, cachaça industrial envelhecida, por 3.1, prestígio, 3.2, imagem boa, e 3.3, uísque nacional. 0 elemento 4, cachaça artesanal envelhecida, por 4.1, prestígio, 4.2, bebida superior, e 4.3, imagem de excelência.

Os significantes 2.1, 3.1 e 4.1, prestígio, significam que as cachaças diferenciadas estão tendo mais atenção da elite da sociedade consumidora, por serem cachaças mais caras e requintadas, com aspectos sensoriais também diferenciados, e, por isso, têm uma imagem positiva. 0 significante 2.2 , obra de arte é a prova do requinte, significando que a cachaça artesanal é feita de forma peculiar, resultando em um produto de excelência. Os significantes 2.3 e 4.2, bebida superior, significam que a cachaça artesanal é uma bebida com padrão de qualidade mais elevado em relação à industrial. Os significantes 2.4 e 4.3, imagem de excelência, também se referem, especificamente, às cachaças artesanais, demonstrando que a sua imagem é a melhor de todas. 0 elemento 3.2, imagem boa, significa que a imagem da cachaça industrial envelhecida é boa; no entanto, inferior às artesanais (branca e envelhecida), contudo melhor que a imagem da "branquinha". Nesse sentido, identifica-se uma hierarquia de imagens, em que as artesanais ficam em primeiro lugar, com uma clara imagem de excelência; a 
industrial envelhecida, em segundo, com uma imagem boa; e, por último, a "branquinha", com uma imagem desprestigiada. 0 significante 3.3 , uisque nacional, demonstra como a cachaça foi apresentada ao Brasil de uma forma "melhorada". Tornar-se um uísque é diferente de ser cachaça. Então, a imitação do estrangeirismo, segundo Ribeiro (1983), influenciaria a aceitação da bebida denominada dessa forma.

Nota-se que a representação estigmatizada da cachaça é devida à sua origem pobre (CASCUDO, 2006), fabricada por escravos e consumida, inicialmente, por eles e pessoas de baixa renda. Vale ressaltar que, apenas quando o significante cachaça é acompanhado de adjetivos como artesanal, envelhecida e artesanal envelhecida, a representação cultural estigmatizada afasta-se do significante. Mas, como a pesquisa não está tratando especificamente desses diferenciais de cachaça, e sim de seu significante simples cachaça -, usou-se a representação cultural, de um modo geral, como estigmatizada neste artigo.

No elemento 5, público, significado por 5.1, trabalhador, 5.2, pobre, 5.3, classe média, e 5.4 , elite, identifica-se que todas as classes sociais consomem o produto, no entanto a imagem da cachaça, ainda assim, é permeada por estigmas ruins. Com base em uma leitura marxista, identifica-se uma questão antagônica entre a representação da cachaça como bebida para pobre e não para elite, enfatizando que Marx tratava das manifestações negativas do pensamento burguês (HALL, 2003).

0 antagonismo retrata a representação

diferenciada entre as classes, porque uma bebida que veio da "senzala" não poderia fazer sucesso na "casa grande", nessa perspectiva ideológica. Assim, apesar de ser consumida em todas as classes, ela ainda é "mal vista" pelas elites.

Em se tratando de Althusser (2001), a classe dominante pode exercer seu poder econômico, político e ideológico através dos aparelhos ideológicos de Estado e passar a dominar uma situação. No caso, a representação cultural da cachaça torna-se estigmatizada pela imposição de classe. Daí a representação é repassada para as demais pessoas, através da interpelação do sujeito, que ao nascer já toma como certo a representação como negativa.

Por meio do conceito de deformação de Paul Ricouer (1977), o processo de vida real deixa de constituir a base para ser substituído por aquilo que os homens dizem e representam, 0 que faz a imagem ser tomada como real. Dessa forma, as representações culturais da cachaça, estigmatizadas, são tomadas como o real. Logo, apesar de todas as classes sociais consumirem a bebida, o público que realmente a representa são as classes mais pobres.

Resultado: surge o mito da bebida popular.

0 elemento 6 , espaço geográfico, significado por 6.1, Brasil, e 6.2, exterior, demonstra as 
diferentes representações no Brasil e no exterior.

No Brasil, a cachaça possui uma conotação negativa devido à sua origem. Entretanto, no exterior, não há mitos que estigmatizem a cachaça. Desde 1968, por exemplo, a bebida é oficialmente exportada para a Alemanha e, aos poucos, as exportações se expandiram. Hoje, segundo o SEBRAE (2008), a cachaça pode ser encontrada em quase todo o mundo.

Segundo Hall (1997a; 1997b), isso acontece porque os significados são produzidos entre os sujeitos de uma cultura. Portanto, no exterior a cachaça significa o próprio espírito do Brasil. $\mathrm{Na}$ perspectiva de Câmara (2004), ela representa o samba, o futebol, o carnaval, entre outros aspectos culturais brasileiros, reconhecidos no mundo. De fato, a sua representação cultural no exterior não tem estigmas ruins.

Resultado: surge o mito do Brazilian brandy.

0 elemento 7, preço, significado por 7.1, Brasil, 7.2, exterior, e 7.3, barato, determina as diferenças de preço da cachaça. No Brasil, a maior parte da cachaça produzida custa barato e a precificação fornece subsídios para a estigmatização, pautada na ideologia de que tudo que é barato é ruim. Fato que também pode ser explicado pelo conceito de deformação de Paul Ricouer (1977), constatando que o real é a imagem da cachaça barata. Não é possível negar que também existam cachaças que custam caro no Brasil. Mas são poucas. A rigor, no imaginário dos brasileiros, cachaça custa pouco. E, para eles, custa pouco porque é ruim, reforçando, assim, o mito da bebida popular. Contudo, no exterior, a história é diferente. Com a ausência da estigmatização, a cachaça custa caro: em média, quatorze euros a garrafa, o que equivale, no Brasil, hoje, a dez vezes mais que 0 valor vendido no mercado interno.

Resultado: este fato ajuda a reforçar o mito do Brazilian brandy .

0 elemento 8, antes versus hoje, significado pelos significantes 8.1, ruim versus boa, 8.2, ruim versus regular, e 8.3, ruim versus ruim, retrata diferentes opiniões acerca da representação da cachaça. Existe uma concordância em relação ao antes, que se originou com estigmas ruins. Contudo, em relação ao hoje, muitas são as opiniões acerca da representação. Boa é provável que não seja, pois, como foi exposto na problemática, existem mitos permeando a representação da bebida. Assim, a recepção da representação é influenciada pela forma como os mitos mascaram continuamente a realidade (BARTHES, 1993). Ruim, sabe-se que já foi, devido à sua formação (CASCUDO, 2006). No entanto, a representação tem sido influenciada pela representação positiva, ligada aos aspectos culturais brasileiros no exterior, demonstrando, nesse sentido, a formação de um mito da moda da cachaça. Dessa forma, acredita-se que ela se apresente de maneira diferente da sua origem negativa. Então, não pode ser ruim também. 0 significante regular parece ser plausível 
para conotar a representação, já que é o ponto

intermediário entre os dois outros, demonstrando uma "suavizada" na representação negativa, mas que não a modifica suficientemente para torná-la positiva.

Resultado: surge o mito "da moda".

\subsection{Mitos da representação cultural da cachaça}

De acordo com Barthes (1993), o mito é formado pela metalinguagem, ou segundo sistema de significação de um signo, conforme previamente discutido. E, com base nesse pressuposto, observa-se, em sequência, a seguir, os mitos da representação cultural da cachaça identificados neste trabalho.

Cinco elementos, dos oito encontrados, do repertório de representação cultural formaram os mitos. 0 elemento 1, "branquinha", gerou os mitos do cachaceiro e do desprestígio.

Os elementos 5 e 7, público e preço, levaram ao mito bebida popular. Os elementos $6 \mathrm{e}$ 7, espaço geográfico e preço, resultaram no mito: Brazilian brandy. 0 elemento 8, antes versus hoje, formou o mito da moda. Os elementos 2, 3 e 4, cachaça artesanal, cachaça industrial envelhecida e cachaça artesanal envelhecida, não geraram mitos porque não tratam do significante cachaça unicamente, mas acompanhado de adjetivos, conforme mencionado na interpretação ideológica da representação. Observam-se a seguir, mais detalhadamente, os mitos.

\subsubsection{Cachaceiro}

0 cachaceiro representa os estigmas negativos relacionados à identidade do consumidor de cachaça. 0 termo não representa apenas 0 consumidor, mas também a embriaguez causada pela cachaça ou por qualquer outra bebida alcoólica, incluindo os constrangimentos sociais levados por ela.

Devido a este mito, a identidade do cachaceiro continua sendo repudiada. A elite e a classe média parecem não pretender associar suas identidades a ela através do consumo - consumo que é, de fato, um processo de criação de identidades. Grosso modo, apenas as pessoas de baixa renda, que frequentemente tomam cachaça, têm suas identidades associadas ao cachaceiro. Assim, o mito fortalece a representação cultural negativa da cachaça.

\subsubsection{Desprestígio}

0 mito do desprestígio está relacionado ao principal público consumidor de cachaça e à identidade do cachaceiro, que, separadamente, também é um mito, como se pode observar.

No imaginário das pessoas: a) a cachaça era destinada apenas aos pobres, apesar de se contatar que tal fato não é verídico, tendo em vista a existência de cachaças diferenciadas, destinadas a outros públicos; e b) o consumidor desta bebida é um "cachaceiro" - no sentido pejorativo da palavra -, representando a 
embriaguez e os males sociais decorrentes do consumo.

Mesmo sendo o destilado mais consumido do Brasil, a "branquinha" sofre, ainda hoje, preconceitos na cultura brasileira. 0 significante "cachaça", de maneira geral, representa desprestígio. Reforçando, assim, a estigmatização da representação cultural.

\subsubsection{Bebida popular}

0 mito da bebida popular é oriundo do público consumidor da cachaça e do preço baixo pelo qual ela é frequentemente vendida, preço este que não se torna significante apenas do significado de acessibilidade a todas as classes, mas também de inferioridade. Mitos advindos da crença de que tudo que é barato é ruim reforçam a "inferioridade" do produto.

0 mito da bebida popular - barata e destinada a pessoas de baixa renda - está cristalizado, há muito, na cultura brasileira e reforça a estigmatização negativa da representação.

\subsubsection{Brazilian brandy}

A representação cultural da cachaça "tipo exportação" é melhor que a comercializada no mercado interno, embora sejam o mesmo produto, modificando apenas embalagem e rótulo. A cachaça tipo exportação não significa apenas um produto destinado ao exterior, mas um produto melhor.

Fora do Brasil - a exemplo de Alemanha e de Portugal -, a história da cachaça é diferente.
Com exportações anuais de ordem crescente, a cachaça é, hoje, um dos destilados mais consumidos no mundo. Vale ressaltar que, no exterior, o seu preço é mais alto, quando comparado ao preço praticado no mercado interno brasileiro. Em verdade, no exterior, a cachaça é vista como um produto típico do Brasil e é relacionada a aspectos culturais reconhecidos universalmente como brasileiros.

A rigor, este mito não contribui à criação de estigmas negativos para a representação cultural. Pelo contrário, ele ajuda a suavizar o preconceito sobre a cachaça, demonstrando que a bebida remete a um produto bem aceito mundialmente.

\subsubsection{Da moda}

É inegável que a cachaça, desde a sua origem, adquiriu uma imagem estigmatizada. No entanto, há indícios de que ela vem tendo a sua representação modificada ao longo do tempo, por causa, sobretudo, das influências da representação positiva no exterior.

Possivelmente, a representação negativa da cachaça no Brasil ainda não regrediu por completo. É preciso mais tempo para que a representação positiva surta efeitos junto aos brasileiros e ao marketing.

Especula-se que a cachaça está em "alta", que não mais é bebida de pobre, que todas as classes sociais a consomem, contudo isso parece não passar de um modismo. De fato, os preconceitos contra a cachaça são advindos de ideias 
enraizadas na cultura brasileira e, portanto, a sua ressignificação não seria em tão curto prazo.

Ao se reconhecer a cachaça como uma bebida "da moda", há de se reconhecer também a importância da "bebida 'da moda"' como um elemento que melhora sua imagem. Na realidade, este mito, assim como 0 do Brazilian brandy, ajuda a suavizar o preconceito contra a cachaça.

\section{Conclusão}

Ao contrário do que se pensava no início deste estudo, os mitos não atribuem única e exclusivamente conotações negativas à cachaça no Brasil. De fato, atribuem também conotações positivas. Entretanto, os mitos positivos não conseguem ressignificar a representação cultural da cachaça e fazer com que ela se torne uma preferência nacional, em todas as classes sociais.

Nesse sentido, não é uma ação de empresas isoladas, ou de governo, ou de marketing - esta última, aquela que 0 setor parece julgar ser a mais eficaz -, que minimizará a estigmatização da imagem da cachaça e do seu consumo, mas sim uma política conjunta entre os envolvidos.

Grosso modo, não existem ações políticas conjuntas. Os envolvidos com o setor não formam uma rede coesa para lutar por ideologias comuns a eles, como o melhoramento da representação cultural da cachaça no Brasil.
Ao contrário, as empresas do setor, por exemplo, agem individualmente. Elas veiculam campanhas publicitárias que não demonstram a realidade e, portanto, não atingem o povo brasileiro. Esse é 0 caso das campanhas que mostram jovens bonitos, bem vestidos, em lugares atraentes, bebendo cachaças industriais, quando se sabe que eles não são o público-alvo desse tipo de cachaça. $\mathrm{E}$, assim, têm-se, em verdade, um discurso vazio.

A representação estigmatizada da cachaça no Brasil, enraizada há séculos, só poderá ser revertida no campo cultural em médio e longo prazos. E isso só ocorrerá a partir do momento em que o povo brasileiro a compreender como um dos elementos da sua identidade - elemento que deve ser reconhecido como um símbolo nacional, uma amostra da criatividade e da persistência de um povo, e, sobretudo, das suas classes menos privilegiadas.

Aceitar que se atribua à cachaça uma imagem exagerada e exclusivamente negativa é um desserviço à cultura popular brasileira. A rigor, tal aceitação parece interessar a uma elite nacional preconceituosa, além de aos setores de bebidas concorrentes.

Os mitos Brazilian brandy e da moda - surgidos a partir do senso comum e aproveitados, oportunamente, pela mídia - são exemplos iniciais de soluções de ressignificação à cachaça. Um processo de estigmatização que se desenvolveu no Brasil a partir do período colonial 
naturalmente não será ressignificado com facilidade. Afinal, são séculos de uma imagem desfavorável, frente a algumas décadas de esforço em sentido contrário.

\section{Referências}

ALTHUSSER, Louis. Aparelhos ideológicos de estado: nota sobre os aparelhos ideológicos de estado. 8. ed. Rio de Janeiro: Graal, 2001. 127 p.

BARBOSA, Lívia; CAMPBELL, Collin. Cultura, consumo e identidade. Rio de Janeiro: FGV, 2006.

BARTHES, Roland. Elementos de semiologia. 11. ed. São Paulo: Cultrix, 1996.

Mitologias. 9. ed. Rio de Janeiro: Bertrand Brasil, 1993.

BERGMANN, Leila Mury. Manifestações dos alunos sobre professores/escola no Orkut. In: SIMPÓSIO INTERNACIONAL DE ESTUDOS DE GÊNEROS TEXTUAIS (SIGET), 4., 2007, Tubarão. Anais... Simpósio Internacional de Estudos de Gêneros Textuais: Tubarão, 2007.

CÂMARA, Marcelo. Cachaça: prazer brasileiro. Rio de Janeiro: Mauad, 2004.

CAMPOS, Miriam Píber. A mídia colaborando na constituição dos corpos na contemporaneidade. In: SEMINÁRIO FAZENDO GÊNERO, 7., 2006, Florianópolis. Anais... Florianópolis: Seminário Fazendo Gênero, 2006.

CASCUD0, Luís da Câmara. Prelúdio da cachaça. São Paulo: Global, 2006.

CHARTIER, Roger. A história cultural: entre práticas e representações. 2. ed. Algés (Portugal): DIFUSEL Difusão Editorial S/A, 2002.

FREIRE FILH0, João. Força de expressão: construção, consumo e contestação das representações midiáticas das minorias. In: SOCIEDADE BRASILEIRA DE
ESTUDOS INTERDISCIPLINARES DA COMUNICAÇÃO (Intercom), 28., 2005, Rio de Janeiro. Anais... Rio de Janeiro: Intercom, 5-9 set. 2005. [CD-ROM]

GARCIA, Adriana Domingues; ROCHA, Sibila; HINERASKY, Daniela. 0 gaúcho na tela: a representação da identidade cultural regional na série histórias curtas. In: SOCIEDADE BRASILEIRA DE ESTUDOS INTERDISCIPLINARES DA COMUNICAÇÃO (Intercom), 30., 2007, São Paulo. Anais... São Paulo: Intercom, ago./set. 2007. [CD-ROM]

GUERRA, Vânia Maria Lescano. Discurso, representação e relações intersemióticas. Estudos lingüísticos, Campinas, n. XXXV, p. 1970-1980, 2006.

HALL, Stuart. 0 problema da ideologia: o marxismo sem garantias. In: Da diáspora: identidades e mediações culturais. Organização: Liv Sovik. Tradução: Adelaine La Guardia Resende et al. Belo Horizonte: UFMG; Brasília: Representação da UNESCO no Brasil, 2003. p. 265-293.

(ed.). Representation: cultural representations and signifying practices. London: Sage Publications Ltd., 1997a.

The work of representation. In: HALL, Stuart. (ed.). Representation: cultural representations and signifying practices. London (UK): Sage Publications Ltd., 1997b. p. 13-74.

MILLER, Daniel. Consumption and its consequences. In: MACKAY, Hugh. (ed.). Consumption and everyday life. London: Sage Publications Ltd., 1997. p. 13-50. MOUFFE, Chantal. 0 Regresso do político. Lisboa: Gradiva, 1996.

RIBEIRO, Darcy. Teoria do Brasil: os brasileiros. 7. ed. Petrópolis: Vozes, 1983.

RICOUER, Paul. Interpretação e ideologias. Rio de Janeiro: F. Alves, 1977.

SEBRAE - Serviço de Apoio as Pequenas Empresas. Cachaça artesanal. Estudos de mercado Sebrae/ 
ESPM. [Relatório completo]. Sebrae, 2008. Disponível em: <http://www.biblioteca.sebrae.com.br/bds/BDS. nsf/32D45A5E7EE50293832574DC004574B0/\$File/ NT0003905A.pdf>. Acesso em: 15 dez. 2008.

SGARBIERI, Astrid Nilsson. Representações do gênero feminino da mídia impressa. Estudos linguísticos, Campinas, n. XXXV, p. 386-371, 2006.

SLATER, Don. Cultura do consumo e modernidade.

São Paulo: Nobel, 2002.

SOUZA, Andréa Bittencourt de. Billy Elliot: representações de gênero e sexualidade ensinando um modo de ser bailarino. In: SEMINÁRIO INTERNACIONAL FAZENDO GÊNERO, 7., 2006, Florianópolis. Anais... Florianópolis: Seminário Internacional Fazendo Gênero, 2006.

THIRY-CHERQUES, Hermano Roberto. Métodos estruturalistas: pesquisa em ciência de gestão. São Paulo: Atlas, 2008.

WOODWARD, Kathryn. Identidade e diferença: uma introdução teórica e conceitual. In: SILVA, Tomaz Tadeu da; HALL, Stuart; WOODWARD, Kathryn. (orgs.). Identidade e diferença: a perspectiva dos estudos culturais. Petrópolis: Vozes, 2000. 
The mythology in the cultural representation of the cachaça: negative image and attempt to reframe

\section{Abstract}

The myths that permeate "cachaça" in the Brazilian culture were identified, based on the fact that they favor the negative cultural representation - the image of an object on a particular culture - of this drink. It was constituted a corpus of research characterized by establishing significant links with the social practice in focus. The methodology adopted was semiology. Thus, five myths related to the cultural representation of the "cachaça" were identified: "drunkard", "discredit", "popular drink", "Brazilian brandy" and "fashion". It was concluded that, contrary to what was thought before the beginning of the study, the myths do not assign solely and exclusively negative connotations to the cachaça in Brazil. They also give it positive connotations. However, the positive myths cannot yet reformulate a new meaning to the cultural representation of this drink.

\section{Keywords}

Cachaça. Cultural representation. Mythology.

\section{La mitología en la representación cultural de la cachaça: imagen negativa e intento de resignificación}

\section{Resumen}

Fueron identificados los mitos que permean la cachaça en la cultura brasileña, basada en el hecho de que están a favor de la representación cultural - la imagen de un objeto en una cultura particular - negativa de esta bebida. Se constituyó un corpus de investigación caracterizado por establecer vínculos significativos con la práctica social en enfoque. La metodología adoptada fue la semiología. Así, fueron identificados cinco mitos relacionados con la representación cultural de cachaça: "borracho", "desprestigio", "bebida popular", "brandy de Brasil" y "de moda". Se concluyó que, contrariamente a lo que se pensaba antes del inicio del estudio, los mitos no se atribuyen únicamente a las connotaciones negativas de la cachaça de Brasil. Le asignan también una connotación positiva. Sin embargo, los mitos positivos todavía no pueden reformular la representación cultural de esta bebida.

\section{Palabras clave}

Cachaça. Representación cultural. Mitología. 


\section{Expediente}

A revista E-Compós é a publicação científica em formato eletrônico da Associação Nacional dos Programas de Pós-Graduação em Comunicação (Compós). Lançada em 2004, tem como principal finalidade difundir a produção acadêmica de pesquisadores da área de Comunicação, inseridos em instituições do Brasil e do exterior.
E-COMPÓS I www.e-compos.org.br I E-ISSN 1808-2599

Revista da Associação Nacional dos Programas de Pós-Graduação em Comunicação. Brasília, v.13, n.1, jan./abr. 2010.

A identificação das edições, a partir de 2008 passa a ser volume anual com três números.

\section{CONSELHO EDITORIAL}

Afonso Albuquerque

Universidade Federal Fluminense, Brasil

Alberto Carlos Augusto Klein

Universidade Estadual de Londrina, Brasil

Alex Fernando Teixeira Primo

Universidade Federal do Rio Grande do Sul, Brasil

Alfredo Vizeu

Universidade Federal de Pernambuco, Brasil

Ana Carolina Damboriarena Escosteguy

Pontifícia Universidade Católica do Rio Grande do Sul, Brasil

Ana Silvia Lopes Davi Médola

Universidade Estadual Paulista, Brasil

André Luiz Martins Lemos

Universidade Federal da Bahia, Brasil

Ângela Freire Prysthon

Universidade Federal de Pernambuco, Brasil

Antônio Fausto Neto

Universidade do Vale do Rio dos Sinos, Brasil

Antonio Carlos Hohlfeldt

Pontifícia Universidade Católica do Rio Grande do Sul, Brasil

Arlindo Ribeiro Machado

Universidade de São Paulo, Brasil

César Geraldo Guimarães

Universidade Federal de Minas Gerais, Brasil

Cristiane Freitas Gutfreind

Pontifícia Universidade Católica do Rio Grande do Sul, Brasil

Denilson Lopes

Universidade Federal do Rio de Janeiro, Brasil

Eduardo Peñuela Cañizal

Universidade Paulista, Brasil

Erick Felinto de Oliveira

Universidade do Estado do Rio de Janeiro, Brasil

Francisco Menezes Martins

Universidade Tuiuti do Paraná, Brasil

Gelson Santana

Universidade Anhembi/Morumbi, Brasil

Goiamérico Felício

Universidade Federal de Goiás, Brasil

Hector Ospina

Universidad de Manizales, Colômbia

Herom Vargas

Universidade Municipal de São Caetano do Sul, Brasil

leda Tucherman

Universidade Federal do Rio de Janeiro, Brasil

Itania Maria Mota Gomes

Universidade Federal da Bahia, Brasil

Janice Caiafa

Universidade Federal do Rio de Janeiro, Brasil

Jeder Silveira Janotti Junior

Universidade Federal da Bahia, Brasil
João Freire Filho

Universidade Federal do Rio de Janeiro, Brasil

John DH Downing

University of Texas at Austin, Estados Unidos

José Luiz Aidar Prado

Pontifícia Universidade Católica de São Paulo, Brasil

José Luiz Warren Jardim Gomes Braga

Universidade do Vale do Rio dos Sinos, Brasil

Juremir Machado da Silva

Pontifícia Universidade Católica do Rio Grande do Sul, Brasil

Lorraine Leu

University of Bristol, Grã-Bretanha

Luiz Claudio Martino

Universidade de Brasília, Brasil

Maria Immacolata Vassallo de Lopes

Universidade de São Paulo, Brasil

Maria Lucia Santaella

Pontifícia Universidade Católica de São Paulo, Brasil

Mauro Pereira Porto

Tulane University, Estados Unidos

Muniz Sodre de Araujo Cabra

Universidade Federal do Rio de Janeiro, Brasil

Nilda Aparecida Jacks

Universidade Federal do Rio Grande do Sul, Brasil

Paulo Roberto Gibaldi Vaz

Universidade Federal do Rio de Janeiro, Brasil

Renato Cordeiro Gomes

Pontifícia Universidade Católica do Rio de Janeiro, Brasil

Ronaldo George Helal

Universidade do Estado do Rio de Janeiro, Brasil

Rosana de Lima Soares

Universidade de São Paulo, Brasil

Rossana Reguillo

Instituto Tecnológico y de Estudios Superiores do Occidente, México

Rousiley Celi Moreira Maia

Universidade Federal de Minas Gerais, Brasil

Samuel Paiva

Universidade Federal de São Carlos, Brasil

Sebastião Albano

Universidade Federal do Rio Grande do Norte, Brasil

Sebastião Carlos de Morais Squirra

Universidade Metodista de São Paulo, Brasil

Simone Maria Andrade Pereira de Sá

Universidade Federal Fluminense, Brasil

Suzete Venturelli

Universidade de Brasília, Brasil

Valério Cruz Brittos

Universidade do Vale do Rio dos Sinos, Brasil

Veneza Mayora Ronsini

Universidade Federal de Santa Maria, Brasil

Vera Regina Veiga França

Universidade Federal de Minas Gerais, Brasil

\section{COMISSÃO EDITORIAL}

Felipe da Costa Trotta I Universidade Federal de Pernambuco, Brasil Rose Melo Rocha I Escola Superior de Propaganda e Marketing, Brasil CONSULTORES AD HOC

João Maia I Universidade do Estado do Rio de Janeiro, Brasil Sandra Gonçalves I Universidade Federal do Rio Grande do Sul, Brasil Mayra Rodrigues Gomes I Universidade de São Paulo, Brasil Gisela Castro I Escola Superior de Propaganda e Marketing, Brasil João Carrascoza I Escola Superior de Propaganda e Marketing, Brasil Luciana Pellin Mielniczuk I Universidade Federal de Santa Maria, Brasil Irene de Araújo Machado I Universidade de São Paulo, Brasil Hermilio Pereira dos Santos Filho I Pontifícia Universidade Católica, Brasil Benjamim Picado I Universidade Federal Fluminense, Brasil Maria Apaecida Baccega I Escola Superior de Propaganda e Marketing, Brasil Rogério Ferraraz I Universidade Anhembi Morumbi, Brasil

Bruno Souza Leal I Universidade Federal de Minas Gerais, Brasi REVISÃO DE TEXTO E TRADUÇÃo I Everton Cardoso EDITORAÇ̃̃ ELETRÔNICA I Roka Estúdio
COMPóS I www.compos.org.br

Associação Nacional dos Programas de Pós-Graduação em Comunicação

Presidente

Itania Maria Mota Gomes

Universidade Federal da Bahia, Brasil

itania@ufba.br

Vice-presidente

Julio Pinto

Pontifícia Universidade Católica de Minas Gerais, Brasil juliopinto@pucminas.br

Secretária-Geral

Ana Carolina Escosteguy

Pontifícia Universidade Católica do Rio Grande do Sul, Brasil carolad@pucrs.br 